\title{
Occurrence of zearalenone in wheat- and corn-based products commercialized in the State of Paraná, Brazil
}

\author{
Giovanna Caputo Almeida-Ferreira ${ }^{1}$, Ione Parra Barbosa-Tessmann ${ }^{2}$, Rose Sega ${ }^{3}$, \\ Miguel Machinski Junior ${ }^{1}$ \\ ${ }^{1}$ Departamento de Ciências Básicas da Saúde, Universidade Estadual de Maringá, Maringá, PR, Brazil. \\ ${ }^{2}$ Departamento de Bioquímica, Universidade Estadual de Maringá, Maringá, PR, Brazil. \\ ${ }^{3}$ Vigilância Sanitária de Alimentos, Secretaria do Estado da Saúde do Paraná, Curitiba, PR, Brazil.
}

Submitted: March 11, 2011; Approved: September 10, 2012.

\begin{abstract}
The productivity of wheat and corn crops depends on climatic conditions and resistance against phytopathogenic fungi such as those of the genus Fusarium. Some species of this genus produce zearalenone (ZEA), a mycotoxin with hyperestrogenic effects. The objective of this study was to investigate the presence of ZEA in samples of cracked wheat $(n=109)$, popcorn $(n=51)$ and corn grits $(n=50)$ commercialized in the State of Paraná, Brazil. Commercial samples of each crop were collected between September 2007 and June 2008 and analyzed by thin-layer chromatography. The method used for detection of the mycotoxin in wheat and corn derivatives presented a recovery rate of $94.5 \%$ and $99.5 \%$, respectively, detection limit of $40 \mu \mathrm{g} \cdot \mathrm{kg}^{-1}$ and quantification limit of $55 \mu \mathrm{g} \cdot \mathrm{kg}^{-1}$. No contamination with ZEA was detected in cracked wheat samples. Among the corn derivatives, only one cracked corn sample was contaminated with ZEA $\left(64 \mu \mathrm{g} \cdot \mathrm{kg}^{-1}\right)$. Despite the low contamination observed, monitoring the occurrence of mycotoxins in foods is important to ensure safety.
\end{abstract}

Key words: wheat, corn, zearalenone, thin-layer chromatography, mycotoxins.

\section{Introduction}

Crops are basic dietary components and are responsible for the calorie intake of the world population. According to the International Grains Council (IGC, 2012), the world grain production was 1.7 billion tons during the 2010/2011 harvest and this figure should be even higher during the 2011/2012 harvest, with an estimated 1.8 billion tons. The contribution of Brazil to the 2010/2011 grain harvest was 162.96 million tons according to the National Supply Company (CONAB, 2012). Important crops in Brazil are corn and wheat, which are mainly produced in the states of Paraná and Rio Grande do Sul (Almeida et al., 2005; Garcia Jr, 2006).

The productivity of each harvest depends on a variety of factors, including diseases that negatively affect crop plantation. In this respect, species of the genus Fusarium comprise a group of phytopathogenic fungi found worldwide (Fink-Gremmels and Malekinejad, 2007). Various species of this group are able to produce zearalenone (ZEA), for example, Fusarium graminearum, F. culmorum and $F$. crookwellense, pathogens of wheat and corn (Glenn, 2007).

ZEA exerts estrogenic disruptors in humans and animals (Kuiper-Goodman et al., 1987). Pigs are the animals most susceptible to the effects of this mycotoxin, with reports of hyperestrogenism demonstrating feminization and testicular atrophy in young males (Haggler et al., 2001). In humans, ZEA can deregulate the hypothalamic-pituitarygonadal (HPG) axis, potentially inducing central precocious puberty (CPP). Studies suggested a possible relationship in the development of CPP and anabolic growth effects in exposed girls to ZEA (Schoental, 1983; Massart et al., 2005, 2008).

Several investigators have reported the incidence of ZEA in corn and wheat in Brazil and in the world (Furlong et al., 1999; Oliveira et al., 2002; Hartmann et al., 2008). 
The production of ZEA depends on seasonal climatic conditions and is more prevalent in cold and humid seasons (Doko et al., 1996). The maximum permitted level (MPL) for ZEA in foods has been regulated in various countries and ranges from 50 to $1000 \mu \mathrm{g} \cdot \mathrm{kg}^{-1}$. In Brazil, the recommended MPL for ZEA is $20 \mu \mathrm{g} \cdot \mathrm{kg}^{-1}$ for baby and infant foods. From 2012 and 2016, the MPL for ZEA will be $300 \mu \mathrm{g} \cdot \mathrm{kg}^{-1}$ in popcorn and corn grits, and $100 \mu \mathrm{g} \cdot \mathrm{kg}^{-1}$ in cracked wheat, respectively (Brasil, 2011).

Studies investigating the occurrence of mycotoxins in foods consumed in Brazil have contributed to a better understanding of this problem and to the elaboration of measures for the prevention of contamination. In view of the high production of wheat and corn in Brazil, especially in the south region, and the conditions favorable for the growth of Fusarium, the objective of the present study was to investigate the occurrence of ZEA in samples of cracked wheat, popcorn and corn grits commercialized in the State of Paraná, Brazil, between September 2007 and June 2008.

\section{Materials and Methods}

\section{Samples}

The municipal and regional sanitary surveillance agencies of the State of Paraná collected 101 samples of corn-based industrial products for human consumption (51 samples of popcorn and 50 samples of corn grits), and 109 samples of cracked wheat commercialized in $18 \mathrm{mu}-$ nicipalities of the State of Paraná between September 2007 and June 2008.

The minimum weight of each sample was $500 \mathrm{~g}$. The samples were ground and homogenized and an aliquot was separated for the determination of water activity $\left(\mathrm{A}_{\mathrm{w}}\right)$. The remaining sample was stored in a plastic bag at $-20{ }^{\circ} \mathrm{C}$ until the time of mycotoxin analysis.

All samples were analysed in duplicate on different days. Spiked samples at concentrations of $480 \mu$ g ZEA. $\mathrm{kg}^{-1}$ to cracked wheat samples and of $320 \mu \mathrm{g} \cdot \mathrm{kg}^{-1}$ to popcorn and corn grits were used to evaluate the efficiency of the extraction process, with each set containing 9 samples. The results of each sample in the batch were corrected for the recovery of the spike.

\section{Determination of water activity}

Water activity was determined in triplicate with an AquaLab 3 water activity meter (Decagon Devices, Inc., Pullman, WA, USA). This equipment uses chilled mirror dew point technology to measure the $\mathrm{A}_{\mathrm{w}}$ of a product. This technique has been approved by the Association of Official Analytical Chemists (AOAC) for the measurement of relative humidity.

\section{Analysis of zearalenone by thin-layer chromatography}

\section{Standard solution}

The working solution was prepared from standard ZEA (Sigma Chemical Co., St. Louis, USA). The stock and working solutions were prepared according to the manual of Official Methods of Analysis of the AOAC (AOAC, 1995). The concentration of ZEA in the stock solution was determined with a Shimadzu UV-1601 PC spectrophotometer (Tokyo, Japan) at $350 \mathrm{~nm}$ and this solution was used for preparation of the standard working solution in benzene containing $40 \mu \mathrm{g}$ ZEA. $\mathrm{mL}^{-1}$.

\section{Optimization of the solvent system for elution of zearalenone from cracked wheat}

The chromatographic conditions for wheat were evaluated in extracts of samples spiked with ZEA. The solvent system was chosen by evaluating the resolution between interfering agents and the mycotoxin. Ten solvent systems cited in the literature for thin-layer chromatography (TLC) and some variations were tested: chloroform-methanol (93:7, v.v ${ }^{-1}$ ) (Howell and Taylor, 1981); chloroformethanol (95:5, v.v $\left.{ }^{-1}\right)$ (Swanson et al., 1984); chloroformethanol $\left(90: 10\right.$, v.v $\left.{ }^{-1}\right)$; chloroform-ethanol $\left(97: 3, v^{-1} \cdot v^{-1}\right)$ (Scott, 1982); chloroform-acetone $\left(96: 4\right.$, v. $\left.^{-1}\right)$ (Thomas et al., 1975); toluene-ethyl acetate-chloroform-formic acid (35:25:25:10, v.v ${ }^{-1} \cdot$ V.v $\left.{ }^{-1}\right)$ (Gimeno, 1983); toluene-ethyl acetate-chloroform-formic acid (50:40:10:10, $\left.\quad \mathrm{v} \cdot \mathrm{v}^{-1} \cdot \mathrm{v} \cdot \mathrm{v}^{-1}\right)$ (Coman et al., 1978); toluene-ethyl acetate-chloroform $\left(60: 30: 10, v^{v} \cdot v^{-1} . v\right)$ (Gimeno, 1983), and chloroform, toluene-acetone $\quad\left(60: 40, \quad v \cdot v^{-1}\right)$ and toluene-acetone $\left(80: 20, v^{-1} v^{-1}\right)$ as variations.

\section{Analytical procedure}

ZEA was analyzed according to the method of Soares and Rodriguez-Amaya (1989). Fifty grams of the sample was homogenized in a blender (Waring Co., Torrington, USA) with $270 \mathrm{~mL}$ methanol (Synth, Diadema, Brazil) and $30 \mathrm{~mL} \mathrm{4 \%} \mathrm{potassium} \mathrm{chloride} \mathrm{(Synth)} \mathrm{for}$ $5 \mathrm{~min}$. The mixture was filtered through common filter paper and $150 \mathrm{~mL}$ of the filtrate was transferred to a beaker. Next, $150 \mathrm{~mL} \quad 30 \%$ ammonium sulfate (Nuclear, Diadema, Brazil) and 20 g Celite (Nuclear) were added and the mixture was left to stand at room temperature for $5 \mathrm{~min}$. The mixture was then filtered through common filter paper, $150 \mathrm{~mL}$ of the filtrate was transferred to a separation funnel, and $150 \mathrm{~mL}$ water was added. This mixture was partitioned twice with $10 \mathrm{~mL}$ chloroform (Vetec, Duque de Caxias, Brazil). Five milliliters of the first and second chloroform partition were combined and evaporated to dryness in a water bath at $60{ }^{\circ} \mathrm{C}$ (EVLAB, model 015T, Londrina, Brazil). The residue obtained was dissolved in $200 \mu \mathrm{L}$ benzene (Merck, Darmstadt, Germany) acetonitrile (Synth) $\left(98: 2, \mathrm{v}^{-\mathrm{v}^{-1}}\right)$. 
For the screening of wheat derivatives, $10 \mu \mathrm{L}$ of the extract was applied to a $20 \times 20 \mathrm{~cm}$ TLC plate (Alugram ${ }^{\circledR}$ SIL G Silica gel 60, Macherey-Nagel, Duren, Germany) $2 \mathrm{~cm}$ from the base line using a manual Nanomat 4 applicator (Camag, Muttenz, Switzerland). The standard was applied in six different concentrations $(20,40,80,120,160$ and 200 ng. $\left.\mathrm{mL}^{-1}\right)$. The plate was placed in an unsaturated chamber containing toluene (Merck)-acetone (Nuclear) $\left(80: 20,{\mathrm{~V} . \mathrm{v}^{-1}}^{-1}\right)$ as solvent system.

For the screening of corn derivatives, $10 \mu \mathrm{L}$ of the extract was applied to a $20 \times 20 \mathrm{~cm}$ TLC plate $2 \mathrm{~cm}$ from the base line using a manual Nanomat 4 applicator. The standard was applied in six different concentrations $(20,40,80$, 120,160 e $200 \mathrm{ng} . \mathrm{mL}^{-1}$ ). The plate was placed in an unsaturated chamber containing toluene (Merck)-ethyl acetate (Nuclear)- chloroform (Vetec)-formic acid (Vetec) $\left(35: 25: 25: 10, \mathrm{~V} \cdot \mathrm{v}^{-1} \cdot \mathrm{V} \cdot \mathrm{v}^{-1}\right)$ for corn-based foods and toluene-acetone $\left(80: 20,{\mathrm{v} . \mathrm{v}^{-1}}^{-1}\right)$ for cracked wheat. ZEA was visualized under ultraviolet light $(366 \mathrm{~nm})$ showing green fluorescence.

For quantification, known volumes of the sample and standard were applied to the TLC plates. After development in the solvent systems described above, ZEA was visualized under ultraviolet light $(366 \mathrm{~nm})$ and quantified by visual comparison. Calculations were performed according to the manual of the Official Methods of Analysis of the AOAC (AOAC, 1995).

\section{Preparation of the derivatizing solution (benzidine)}

At the time of use, equal parts of $0.5 \%$ benzidine solutions ( $0.5 \mathrm{~g}$ benzidine, Merck) were mixed with $20 \mathrm{~mL}$ distilled water containing $1.5 \mathrm{~mL}$ hydrochloric acid (Quimex, Boa Vista, Brazil) and qsp with $100 \mathrm{~mL}$ water and 10\% sodium nitrite (Synth), as described by Malaiyandi et al. (1976).

\section{Confirmation}

The presence of ZEA was confirmed by application in the TLC plate with the benzidine/sodium nitrite derivatizing agent according to Malaiyandi et al. (1976). After drying, ZEA appears as a pink spot. The pink color of this spot becomes more intense and turns red with increasing concentration of the mycotoxin.

\section{Recovery test}

Recovery tests were performed to evaluate the accuracy of the methods. Five samples each of cracked wheat, popcorn and corn grits in which no ZEA was detected were contaminated artificially on the day prior to extraction, with the addition of $480 \mu \mathrm{g} \mathrm{ZEA} \cdot \mathrm{kg}^{-1}$ to cracked wheat samples and of $320 \mu \mathrm{g} \cdot \mathrm{kg}^{-1}$ to popcorn and corn grits. The mycotoxin was then extracted and quantified as described above.

\section{Detection and quantification limits}

The detection limit was the lowest concentration of ZEA visualized by application of standard working solution $\left(40 \mu \mathrm{g}\right.$ ZEA. $\left.\mathrm{mL}^{-1}\right)$ in the TLC plate. The quantification limit was the acceptable lowest concentration $(\mathrm{RSD}<15 \%)$ spiked in six samples each of cracked wheat, popcorn and corn grits in which no ZEA was detected.

\section{Results and Discussion}

For cracked wheat, toluene-acetone $\left(80: 20, v^{-1} v^{-1}\right)$ was efficient for the elution of ZEA. This solvent system provided efficient resolution (Figure 1), reproducibility and rapidity (time of analysis of approximately $30 \mathrm{~min}$ ).

No ZEA was detected in the 109 cracked wheat samples analyzed. Similar results have been reported by Manova and Mladenova (2009), who analyzed 54 wheat grain samples produced in 2007 in Bulgaria by high-performance liquid chromatography (HPLC) and detected only one sample contaminated with ZEA. However, in the same study $58 \%$ of samples were found to be contaminated with ZEA in 2005 and 2006. The authors attributed these results to the fact that contamination of crops with ZEA largely depends on meteorological conditions, with the intense rains that occurred in the previous years favoring fungal growth and mycotoxin production. Martins and Martins (2002) also reported that the production of ZEA depends on environmental conditions.

Cracked wheat is produced from wheat grains by two high-temperature processes (cooking and drying) that remove contaminating fungi (Martins, 2006). However, if the raw material is already contaminated with ZEA, the cooking and drying processes are unable to remove the toxin since ZEA is highly stable at high temperatures (Bennett et al., 1981).

Data regarding the occurrence of ZEA in cracked wheat or other wheat-based products are scarce in the literature. In the study of Vieira et al. (1999) investigating 54

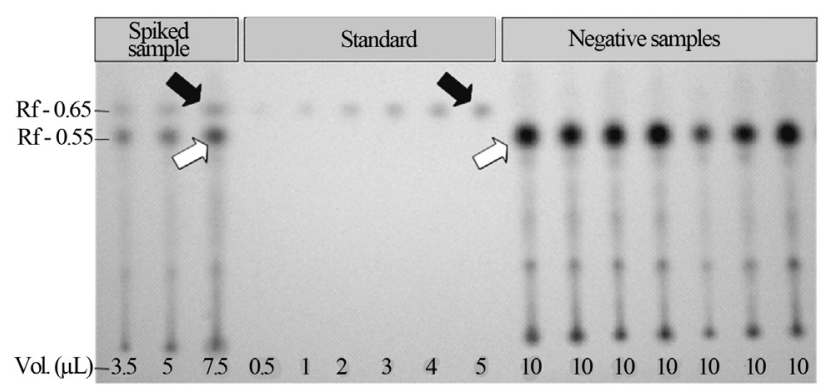

Figure 1 - Separation of zearalenone in wheat samples by thin-layer chromatography. The plate was developed with toluene-acetone (80:20) and the mycotoxin was detected with $0.5 \%$ benzidine and $10 \%$ sodium nitrite as chromogen solution. The white arrow indicates the retention factor $(\mathrm{Rf}=0.55)$ of cracked wheat interfering agents in the spiked sample and in the samples analyzed. The black arrow indicates the Rf $(0.65)$ of zearalenone in the spiked sample and in different volumes of the standard $\left(40 \mu \mathrm{g} \cdot \mathrm{mL}^{-1}\right)$. 
lots of wheat flour samples from Rio Grande do Sul, Brazil, $3.7 \%$ of the samples were found to be contaminated with ZEA, although at low concentrations $\left(26 \mu \mathrm{g} \cdot \mathrm{kg}^{-1}\right)$.

The occurrence of ZEA in corn and corn-based products has been reported by various investigators (Doko et al., 1996; Furlong et al., 1999; Sekiyama et al., 2005). In a survey on ZEA contamination of corn in different regions of Brazil, Silva and Vargas (2001) analyzed 380 fresh corn samples and found that $30(7.8 \%)$ samples were contaminated with the mycotoxin at concentrations ranging from 46.7 to $719 \mu \mathrm{g} . \mathrm{kg}^{-1}$. In contrast, in the present study analyzing 101 corn-based products, only one $(1.0 \%)$ corn grits sample was contaminated with ZEA $\left(64 \mu \mathrm{g} \cdot \mathrm{kg}^{-1}\right)$, with this level being below the recommended by the Brazilian legislation $\left(300 \mu \mathrm{g} \cdot \mathrm{kg}^{-1}\right)$ (Brasil, 2011). The low incidence of ZEA observed in the present study agrees with Oliveira $e t$ al. (2002) who analyzed 24 corn- and rice-based products and found only one sample presenting low-level contamination $\left(8.5 \mu \mathrm{g} \cdot \mathrm{kg}^{-1}\right)$. Similar results have been reported by Sekiyama et al. (2005) investigating 121 corn-based foods commercialized in Maringá, Paraná, Brazil. In that study, only one popcorn sample $(0.8 \%)$ was contaminated with ZEA (448 $\mu \mathrm{g} / \mathrm{kg})$, demonstrating the low incidence of this mycotoxin in industrial products in Brazil.

Water activity and moisture of commercialized products influence the growth of fungi and production of ZEA. According to Almeida et al. (2005), the water activity for growth of the main species of toxigenic fungi should be higher than 0.76 . In the present study, the water activity of cracked wheat, popcorn and corn grits ranged from 0.4 to 0.6 , with a mean $\mathrm{A}_{\mathrm{w}}$ of 0.488 for cracked wheat samples and of 0.512 for corn-based products.

The mean recovery rate of the methods used for the detection of ZEA was significant, with rates of $94.5 \%$ and $99.5 \%$ for cracked wheat samples and corn-based products, respectively. These recoveries are within the recommended range of 70 to $110 \%$ (CAC, 1998). The detection limit of the method was $40 \mu \mathrm{g} \cdot \mathrm{kg}^{-1}$ and the quantification limit was $55 \mu \mathrm{g} \cdot \mathrm{kg}^{-1}$ for wheat and corn samples.

The present results demonstrated a low prevalence of ZEA in corn- and wheat-based industrial products. Nevertheless, constant monitoring of these products is fundamental to ensure the safety, quality and integrity of human food.

\section{Acknowledgments}

The authors thank the Brazilian funding agency Coordenação de Aperfeiçoamento de Pessoal de Nível Superior (CAPES) for granting a Master's fellowship to the first author. We are indebted to the Sanitary Surveillance Agency of the Secretary Office of Health of the State of Paraná for collection of the samples.

\section{References}

Almeida AP, Sabino M, Fonseca H, Corrêa B (2005) Milho recém-colhido no Brasil: interação da microbiota fúngica, fatores abióticos e ocorrência de fumonisinas. Rev Inst Adolfo Lutz 64:1-9.

AOAC - Association of Official Analytical Chemists (1995). Official methods of analysis of the Association of Official Analytical Chemists. The Association of Official Analytical Chemists, Arlington.

Bennett GA, Lagoda AA, Shotwell OL, Hesseltine CM (1981) Utilization of zearalenone-contaminated corn for ethanol production. J Am Oil Chem Soc 58:974-976.

BRASIL (2011). Ministério da Saúde. Agência Nacional de Vigilância Sanitária. $R D C N^{o}$ 7, 18 de fevereiro de 2011, ANVISA, Brasília.

Codex Alimentarius Commission (1998). Criteria for evaluating acceptable methods of analysis for Codex purposes, Codex Committee on Methods of Analysis and Sampling, Documento CX/MAS 98/5

Coman I, Popesc O, Halga P, Grunberg N, Ciudin E (1978) Separation and chromatographic detection of some mycotoxins in fodder raw material. Rev Crest Anim 28:58-61.

CONAB - Companhia Nacional de Abastecimento (2012). Acompanhamento da safra brasileira: grãos - safra 2011/2012 terceiro levantamento. http://www.conab.gov.br/ OlalaCMS/uploads/arquivos/11_12_08_10_58_12_08.pdf.

Doko MB, Brown N, Sydenham EW, Mpuchane S, Siame BA (1996) Natural co-occurrence of fumonisins and zearalenone in cereals and cereal-based foods from Eastern and Southern Africa. J Agric Food Chem 44:3240-3243.

Fink-Gremmels J, Malekinejad H (2007) Clinical effects and biochemical mechanisms associated with exposure to the mycoestrogen zearalenone. Anim Feed Sci Technol 137:326341.

Furlong EB, Soares LMV, Vieira AP, Dadalt G (1999) Aflatoxinas, Ocratoxina e Zearalenona em alimentos da região Sul do Rio Grande do Sul. Rev Inst Adolfo Lutz 58:105-111.

Garcia JrD (2006) Fusarium graminearum em sementes de trigo (Triticum aestivum L.): detecção, efeitos e controles. Piracicaba, 78 p. (Ph.D. Thesis. Escola Superior de Agricultura Luiz de Queiroz, ESALQ).

Gimeno A (1983) Rapid thin layer chromatographic determination of zearalenone in corn, sorghum, and wheat. J Assoc Off Anal Chem 66:565-69.

Glenn AE (2007) Mycotoxigenic Fusarium species in animal feed. Anim Feed Sci Technol 137:199-200.

Haggler WMJr, Towers NR, Mirocha CJ, Eppley RM, Bryden WL (2001) Zearalenone: Mycotoxin or mycoestrogen? In: Summerell, B.A., Leslie, J.F., Bachouse, D., Bryden, W.L., Burges, L.W. (eds.) Fusarium: Paul E. Nelson Memorial Symposium. APS Press, St. Paul, USA, p.321-331.

Hartmann N, Erbs M, Forrer HR, Vogelgsang S, Wettstein FE, Schwarzenbach RP, Bucheli TD (2008) Occurrence of Zearalenone on Fusarium graminearum infected wheat and maize fields in crop organs, soil, and drainage water. Environ Sci Technol 42:5455-5460.

Howell MV, Taylor PW (1981) Determination of aflatoxins, ochratoxin A, and zearalenone in mixed feeds, with detection by thin layer chromatography or high performance liquid chromatography. J Assoc Off Anal Chem 64:1356-63. 
IGC - International Grains Concil (2012). Grain Market Report GMR. $\quad \mathrm{N}^{\mathrm{o}} \quad 419$. http://www.igc.org.uk/downloads/gmrsummary/gmrsumme.pdf.

Kuiper-Goodman T, Scott PcM, Watanabe H (1987) Risk assessment of the mycotoxin zearalenone. Rev Toxicol Pharmacol 7:253-306.

Malaiyandi M, Barrette JP, Wavrock PL (1976) Bis-diazotized benzidine as a spray reagent for detecting zearalenona on thin layer chromatoplates. J Assoc Off Anal Chem 59:959962.

Manova R, Mladenova R (2009) Incidence of zearalenone and fumonisins in Bulgarian cereal production. Food Control 20:362-365.

Massart F, Meucci V, Saggese G, Soldani G (2008) High growth rate of girls with precocious puberty exposed to estrogenic mycotoxins. J Pediatr152:690-695.

Massart F, Seppia P, Pardi D, Lucchesi S, Meossi C, Gagliardi L, Liguori R, Fiore L, Federico G, Saggese G (2005) High incidence of central precocious puberty in a bounded geographic area of northwest Tuscany: an estrogen disrupter epidemic? Gynecol Endocrinol 20:92-98.

Martines E (2006) Resposta Técnica. TECPAR - Instituto de Tecnologia do Paraná. http://sbrtv1.ibict.br/upload/ sbrt2997.pdf?PHPSESSID=eacfd0394bf9cff $\quad 61879 \mathrm{~b}$ $31265 f 473 \mathrm{ef}$

Martins ML, Martins HM (2002) Influence of water activity, temperature and incubation time on the simultaneous production of deoxynivalenol and zearalenone in corn (Zea mays) by Fusarium graminearum. Food Chem 79:315-318.

Oliveira MS, Prado G, Abrantes FM, Santos LG, Veloso T (2002) Incidência de Aflatoxinas, Desoxinivalenol e Zearalenona em produtos comercializados em cidades do estado de Minas Gerais no período de 1998-2000. Rev Inst Adolfo Lutz 6:1-6.

Schoental R (1983) Precocious sexual development in Puerto Rico and oestrogenic mycotoxins (zearalenone). Lancet $1: 537$.

Scott PM (1982) Mycotoxin analysis by TLC. In: Touchstone, J.C. (ed.), Advances in Thin Layer Chromatography. Wiley-Interscience Press, New York, USA, p 321-341.

Sekiyama BL, Ribeiro AB, Machinski PA, Machinski JrM (2005) Aflatoxins, ochratoxin A and zearalenone in maize-based food products. Braz J Microbiol 36:289-294.

Silva CMG, Vargas EA (2001) A survey of zearalenone in corn using Romer Mycosep 224 column and high performance liquid chromatography. Food Addit. Contam., Part A, Chem. Anal. Control Expo. Risk Assess 18:39-45.

Soares LMV, Rodriguez-Amaya DB (1989) Survey of aflatoxins, ochratoxin A, zearalenone and sterigmatocystin in some Brazilian foods by using multi-toxin thin-layer chromatographic method. J Assoc Off Anal Chem 72:22-26.

Swanson SP, Corley RA, White DG, Buck WB (1984) Rapid thin layer chromatographic method for determination of zearalenone and zearalenol in grains and animal feeds. J Assoc Off Anal Chem 67:580-582.

Thomas F, Eppley RM, Trucksess MW (1975) Rapid screening method for aflatoxins and zearalenone in corn. J Assoc Off Anal Chem 58:114-117.

Vieira AP, Badiale-Furlong E, Oliveira MLM (1999) Ocorrência de micotoxinas e características físico-químicas em farinhas comerciais. Cienc Tecnol Aliment 19:221-225.

All the content of the journal, except where otherwise noted, is licensed under a Creative Commons License CC BY-NC. 